\title{
Investigators and Research Site
}

Tim Griffis, University of Minnesota

John Baker, USDA-ARS \& University of Minnesota

Rosemount Research and Outreach Center (RROC), Upper Midwest, St. Paul, Minnesota

3 Flux stations located in corn-soybean Rotation Ecosystems

Funding: September 2003 to 2007. Grant: Office of Science (BER), U.S. Department of Energy, Grant No. DEFG02-03ER63684

\section{Research Objectives}

Our research is designed to improve the scientific understanding of how carbon is cycled between the land and atmosphere within a heavily managed landscape that is characteristic of the Upper Midwest. The Objectives are: 1) Quantify the seasonal and interannual variation of net ecosystem $\mathrm{CO}_{2}$ exchange of agricultural ecosystems in the Upper Midwest grown under different management strategies; 2) Partition net ecosystem $\mathrm{CO}_{2}$ exchange into photosynthesis and ecosystem respiration by combining micrometeorological and stable isotope techniques; 3 ) Examine the seasonal variation in canopy-scale photosynthetic discrimination and the isotope ratios of ecosystem respiration and photosynthesis.

\section{Significant Findings}

\section{The Carbon Balance of Corn-Soybean Rotation Ecosystems Acclimate to Land Management Strategies}

Near-continuous eddy covariance flux measurements have been made in conventional and alternative corn-soybean rotation systems since 2002 to evaluate their carbon sequestration potential. The alternative land management system consists of fall strip tillage combined with a spring and/or fall cover crops. The first complete biennial rotation (2001 through 2003) revealed that both systems were a small net loss of approximately $90 \mathrm{~g} \mathrm{C} \mathrm{m}^{-2}$ to the atmosphere (Baker and Griffis, 2005) indicating that modified tillage practices and the use of a spring oats cover crop had little or no impact on enhancing carbon sequestration. However, experiments involving a winter rye cover crop planted during fall 2004 resulted in an additional $175 \mathrm{~g} \mathrm{C} \mathrm{m}^{-2} \mathrm{y}^{-1}$ (fall 2004 to fall 2005) relative to the conventional treatment. Analyses of flux data collected during the following year (fall 2005 to fall 2006) indicate a substantial enhancement (about 40\%) of ecosystem respiration as microbial activity adjusted to the added substrates (Baker et al., in prep). There is strong evidence that the carbon balance of corn-soybean rotation ecosystems will acclimate to long-term changes in management. From a greenhouse gas management perspective, these findings suggest that the initial carbon gain from cover cropping could be used more effectively as an alternative fuel source (i.e. Ethanol production) rather than attempting to rebuild soil organic matter, which is a relatively slow
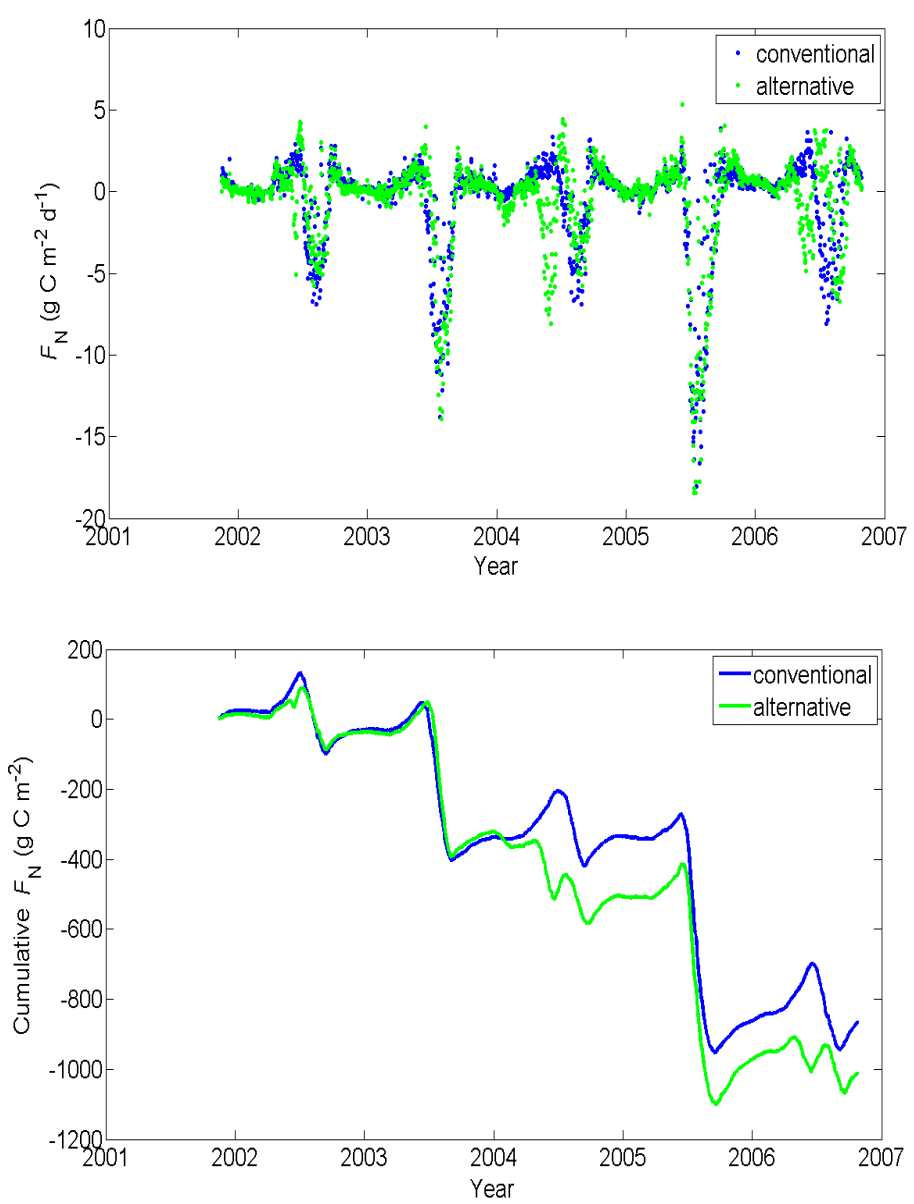
and inefficient process when considering the immediate need to lower atmospheric carbon. The total 5-year $F_{\mathrm{N}}$ for the conventional and alternative systems was $-910 \mathrm{~g} \mathrm{C} \mathrm{m}^{-2}$ and $-1058 \mathrm{~g} \mathrm{C} \mathrm{m}^{-2}$, respectively. Grain harvest removed approximately $1145 \mathrm{~g} \mathrm{C} \mathrm{m}^{-2}$ and $1042 \mathrm{~g} \mathrm{C} \mathrm{m}^{-2}$ resulting in a cumulative 5-year total of $+235 \mathrm{~g} \mathrm{C} \mathrm{m}^{-2}$ (source) and $-16 \mathrm{~g} \mathrm{C} \mathrm{m}^{-2}$ (neutral or weak sink), respectively.

\section{First Direct Measurements of Isotopic $\mathrm{CO}_{2}$ Exchange using the Eddy Covariance Method}

The stable isotope composition of $\mathrm{CO}_{2}$ in the atmosphere represents a potentially important signal of global change (Francey, Tans 1987). Interpreting its variation, however, requires a sound understanding of the underlying biophysical processes. This ultimately requires improved ability to quantify isotopic fluxes between the land and atmosphere. In collaboration with scientists from Campbell Scientific Inc. (Bert Tanner and Steve Sargent) and Yale University (Dr. Xuhui Lee) we conducted the first ever coupled carbon-water isoflux experiment involving three tunable diode laser isotope systems at the University of Minnesota Agricultural AmeriFlux Site during the summer of 2006. The field experiment was conducted over a 60-day period.

Net ecosystem $\mathrm{CO}_{2}$ exchange $\left(F_{\mathrm{N}}\right)$ measured with the EC-TDL system showed strong correlation $\left(r^{2}=0.99\right)$ in the half-hourly fluxes with an eddy covariance open-path infrared gas analyzer (EC-IRGA) over the 60-day period. Net $\mathrm{CO}_{2}$ flux measured with the EC-IRGA and EC-TDL systems agreed to within 6\%. Flux loss associated with diminished frequency response beyond $0.6 \mathrm{~Hz}$ for the EC-TDL system was approximately $18 \%$ during daytime windy $\left(>4 \mathrm{~m} \mathrm{~s}^{-1}\right)$ conditions. There was little evidence of a kinetic-type fractionation effect related to a phase shift among isotopologues due to tube attenuation. Investigation of isotopic spectral similarity in the flux ratio $\left(\delta_{\mathrm{N}}^{x}\right)$ for both ${ }^{13} \mathrm{CO}_{2}$ and $\mathrm{C}^{18} \mathrm{O}^{16} \mathrm{O}$ transport showed that $\delta_{\mathrm{N}}^{x}$ was independent of eddy scale for this ecosystem. Flux loss, therefore, did not significantly bias the $\delta_{\mathrm{N}}^{x} \quad$ estimates. There was excellent agreement between isotopic fluxes measured using the flux-gradient and eddy covariance methods. Further, we provide the first evidence that indirect measurement of the isoflux (i.e. by combining net flux and isotope ratio measurements independently) is equivalent to its direct measurement using the $\mathrm{EC}$ approach. The typical random sampling error associated with eddy covariance flux estimates of $\mathrm{CO}_{2}(\mathrm{EC}-\mathrm{IRGA}),{ }^{12} \mathrm{CO}_{2},{ }^{13} \mathrm{CO}_{2}$, and $\mathrm{C}^{18} \mathrm{O}^{16} \mathrm{O}$ (EC-TDL) was typically $18,23,23$, and $22 \%$, respectively. These errors were highly correlated, dominated by meteorological noise, and showed a strong diurnal pattern - increasing at night due to weaker turbulence and non-stationarity.

An example of the ${ }^{13} \mathrm{CO}_{2}$ isoflux time series, measured with the EC-TDL system and with a TDL flux-gradient system, is shown in the Figure below in the upper left panel and a comparative plot of all simultaneous data collected during the experiment is shown in the upper right panel. These data demonstrate relatively good agreement between both the EC and flux-gradient method, which should be expected over a short canopy when the gradient is resolved above the roughness sublayer. The lower left Figure illustrates the ensemble diurnal pattern of $\delta_{\mathrm{N}}^{13}$ for the flux-gradient and EC-TDL method for the period DOY 221 to DOY 234. While the overall diurnal patterns are qualitatively similar there are a number of important features to note: First, the EC-TDL system showed greater variability from midnight to morning with a greater number of outliers. This was related to weak turbulence and nonstationarity at night. Under these conditions, gradients tend to be relatively large and easier to resolve compared to the eddy covariance terms. Second, the mean standard error of $\delta_{\mathrm{N}}^{13}$ was $4.6 \%$ and $4.1 \%$ for the EC-TDL and FG-TDL systems, respectively. Finally, the EC-TDL midday values were more depleted ( 2 to $5 \%$ ) than those measured by the FG-TDL system, but not statistically significant when considering the measurement errors or a two-sample $t$-test at the $1 \%$ significance level. The diurnal pattern of the isoflux is shown in the lower right Figure and demonstrates excellent agreement between the direct EC measurement $F_{\delta}^{x}=\bar{\rho}_{\mathrm{a}} \overline{w^{\prime}\left[c \delta_{a}^{x}\right]^{\prime}}$ and the approximation based on the EC flux ratio method, $\delta_{\mathrm{N}}^{x} F_{\mathrm{N}}$. This is an exciting result and the first time that this approximation $\delta_{\mathrm{N}}^{x} F_{\mathrm{N}}$ has been validated directly. It demonstrates that the isoflux can be approximated reliably from independent measurement of the total eddy flux and its isotopic ratio as derived from gradient methods. This is significant 
because mass spectrometers and other laser spectroscopy systems that have slower response times, inadequate for EC applications, could be used in the gradient mode to obtain robust estimates of the isoflux.
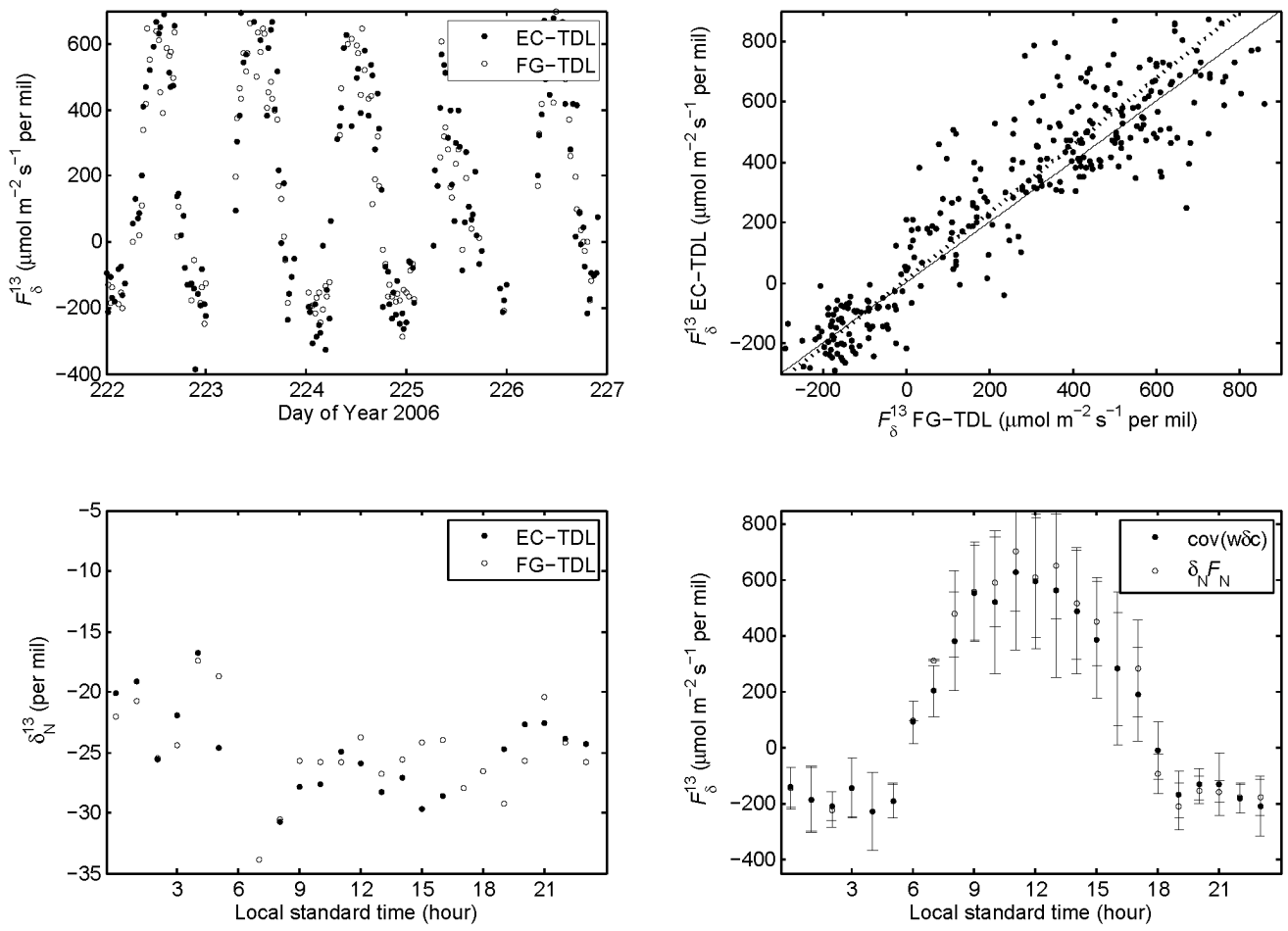

\section{Modeling Isotopic $\mathrm{CO}_{2}$ Exchange and Ecosystem Discrimination}

The datasets we've acquired over the last few years are now being used to develop, parameterize, and test an ecosystem-scale isoflux multilayer model (ESIM) consisting of a 5-layer canopy with shaded and sunlit leaves. We have adapted it to simulate photosynthetic discrimination for $\mathrm{C} 3 / \mathrm{C} 4$ photosynthetic pathways; isotopic fluxes, and ${ }^{13} \mathrm{C}^{16} \mathrm{O}_{2}$ and ${ }^{12} \mathrm{C}^{16} \mathrm{O}_{2}$ mixing ratio profiles using Lagrangian near-field theory. The latter can be used to gain new information on canopy sink/source distribution. The Figure below shows one example of model simulations of the isotopic composition of canopy air (left-hand panel) and the isotopic discrimination of canopy leaves (right-hand panel). In this particular case, the top leaves were more enriched in ${ }^{13} \mathrm{C}$ than bottom leaves, which was related to both light penetration through the canopy and recycling of canopy air. In general the model shows good agreement with isotopic flux measurements and direct measurement of the isotopic composition of canopy leaves. With further development this model will provide a powerful tool for estimating regional-scale estimates of ecosystem discrimination, constraining field to regional scale carbon budgets, and partitioning gross fluxes into their components. 


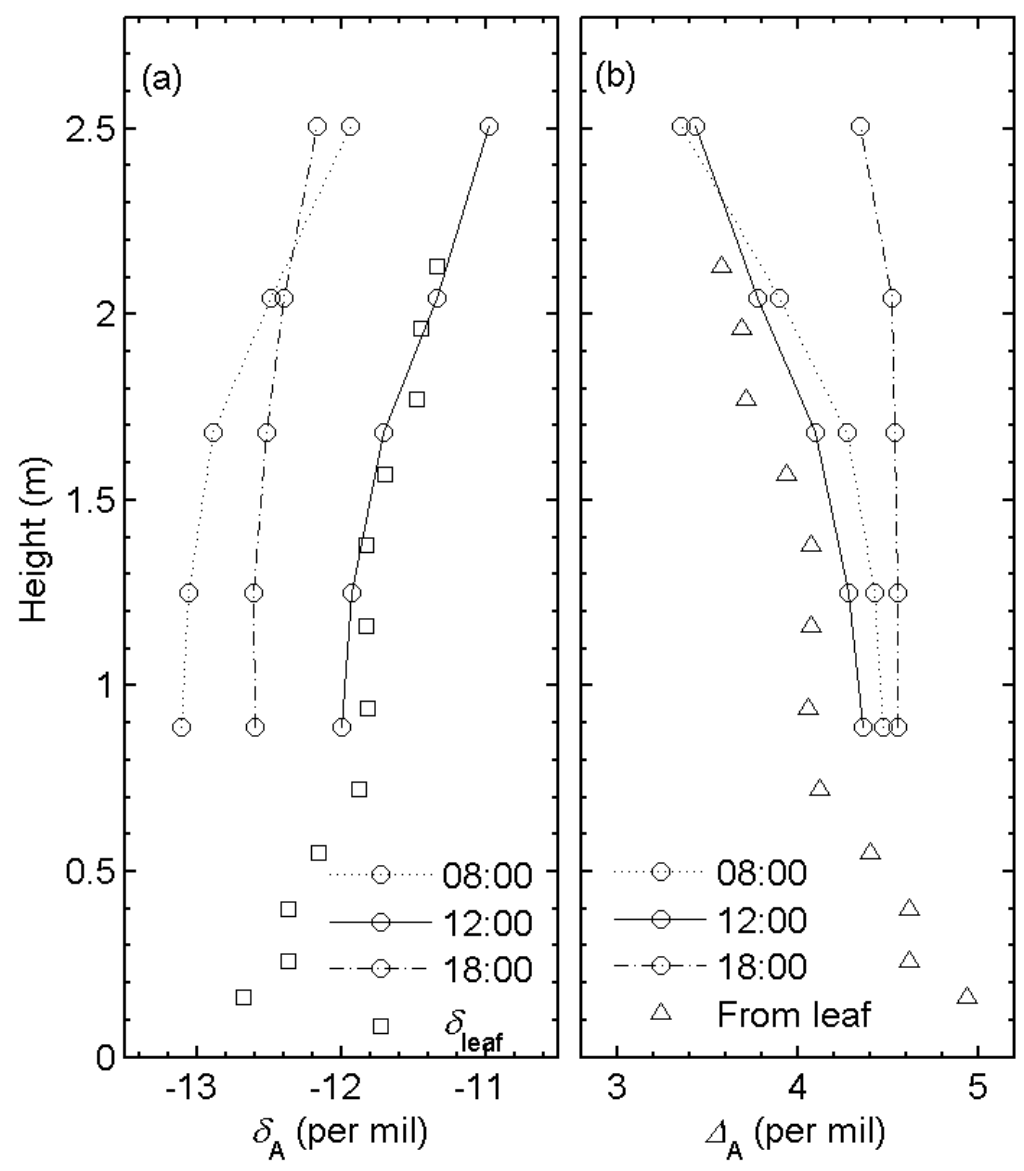

\section{Educational Products}

As new students, postdoctoral fellows, and visiting scientists join our group it is important that they can easily begin working with the meteorological and isotope data that we have been archiving over the last few years. Unfortunately it can often take newcomers a few months to acquire the programming skills necessary to work with such large datasets/databases. This is especially disappointing for summer students who can only visit for 10 or 12 weeks each summer. Over the last year we have developed an exciting database tool that will allow newcomers easy access and analysis of data. Such a tool provides them the capacity to explore data instantly while their programming skills develop to conduct more in depth analyses. This tool was developed by our group using Matlab and we now have a compiled version that we hope to make publicly available within the next few weeks. The tool is available at:

http://www.tc.umn.edu/ smit1729/bdt2.php

A micrometeorological and stable isotope lecture series was developed and integrated into our Biometeorology Graduate course during fall semester 2006. This lecture series incorporated the recent EC-TDL experiments and the long-term (4-years) flux-gradient isotope measurements. We hope to further develop this material by including water vapor isotope techniques and plan to share these lectures on our Biometeorology web site (http://www.biometeorology.umn.edu) once we have completed this task. This lecture material is available upon request. 


\section{Data Products}

We continue to make our data available through our Biometeorology web site. Time of posting is determined by student research progress and pending publications. We have posted data from 2003-2005. Flux data from 2006 is expected to be posted in within the next few weeks.

\section{Training and Development}

DOE funding has helped support 2 undergraduate, 4 graduate, and 1 postdoctoral students. Each student has participated in field and lab work and has gained valuable practical experience working with micrometeorological equipment, and state-of-the-art TDL systems and mass spectrometers. Each student has gained new technical skills related to computer programming and data analyses.

\section{Recent Manuscripts Supported by the Department of Energy, Grant No. DE-FG02-03ER63684}

Baker, J.M., Griffis, T.J., and Ochsner T.E.. Impact of a Winter Rye Cover Crop on the Carbon Balance and Water Use of a Maize-Soybean System, in prep.

Baker, J.M., Ochsner, T.E., Venterea, R.T., and Griffis, T.J. 2006. Tillage and Soil Carbon Sequestration - What Do We Really Know?, Agriculture, Ecosystems, and Environment, 118: 1-5

Baker, J.M. and Griffis T.J. 2005. Examining strategies to improve the carbon balance of corn/soybean agriculture using eddy covariance and mass balance techniques. Agricultural and Forest Meteorology, 128 (3-4), 163-177.

Griffis, T.J., Sargent S.D., Baker J.M., Lee X., Tanner B.D., Greene J., Swiatek E., and Billmark K. 2007. Direct measurement of biosphere-atmosphere Isotopic $\mathrm{CO}_{2}$ exchange using the eddy covariance technique. In prep.

Griffis, T.J., Zhang J., Baker, J.M., Kljun, N., and Billmark, K. 2007. Determining carbon isotope signature from micrometeorological measurements: Implications for studying biosphere-atmosphere exchange processes. BoundaryLayer Meteorology, 123 (2): 201-218, doi: 10.1007/s10546-006-9143-8

Griffis, T.J., Baker, J.M., and Zhang, J. 2005. Seasonal dynamics of isotopic $\mathrm{CO}_{2}$ exchange in a C3/C4 managed ecosystem. Agricultural and Forest Meteorology, 132, 1-19.

Griffis, T.J. Lee, X., Baker J.M., King J.Y., and Sargent S.D. 2005. Feasibility of quantifying ecosystem-atmosphere $\mathrm{C}^{18} \mathrm{O}^{16} \mathrm{O}$ fluxes and discrimination mechanisms using laser spectroscopy, Agricultural and Forest Meteorology, 135, 44-60.

Zhang, J., Griffis T.J., and Baker J.M. 2006. Using continuous stable isotope measurements to partition net ecosystem $\mathrm{CO}_{2}$ exchange. Plant Cell and Environment, doi:10.1111/j.1365-3040.2005.01425.x.

\section{Future Directions}

The new EC-TDL technique has just recently been deployed at our Tall Tower Trace Gas Observatory where we are measuring isotopic fluxes and mixing ratios at heights up to $200 \mathrm{~m}$ above the surface - providing new regional information related to the controls on biosphere-atmosphere isotopic exchange. These new data should be highly valuable to the NACP Midwest Intensive initiative.

\section{For Continued Progress Updates:}

\section{See http://www.Biometeorology.umn.edu}

